\title{
Left-sided pleural effusion in a 47-year-old female
}

\section{Case report}

A 47-year-old female patient was admitted to the Dept of Thoracic Surgery, Gulhane Military Medical Academy (Ankara, Turkey) with right thoraco-abdominal pain, which had been aggravated by cough and deep breathing. Despite being treated with several courses of antibiotics for these symptoms during the previous 2 years, her non-productive cough had worsened. She had been operated on 4 years previously for a hepatic cyst. Laboratory tests were normal. On physical examination, submatite was established on the right lateral thoracic wall along the anterior and posterior axillary lines.

\section{Investigations}

Electrocardiography revealed non-specific changes. Antero-posterior and lateral chest radiography were performed (figure 1).
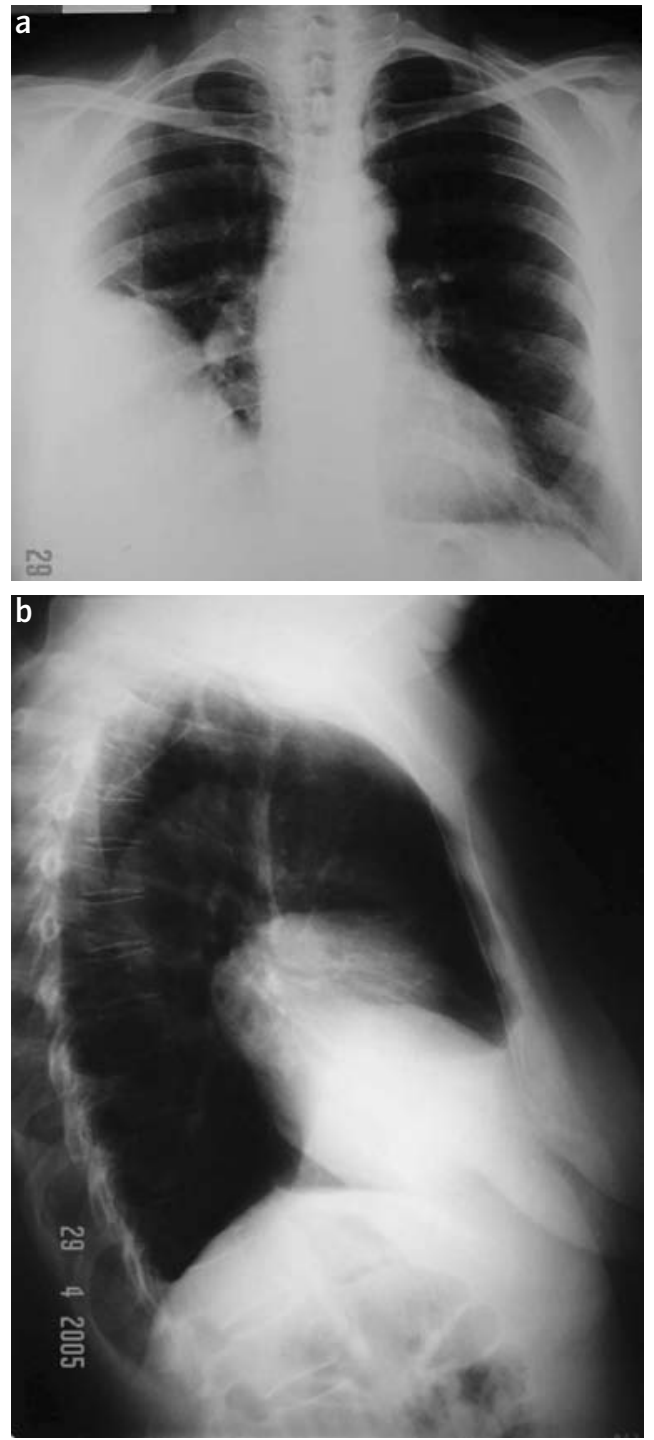
A. Gozubuyuk
S. Gurkok
H. Caylak
O. Yucel
K. Kavakl
M. Dakak
O. Genc

Dept of Thoracic Surgery, Gulhane Military Medical Academy, Ankara, Turkey.

\section{Correspondence:}

S. Gurkok

Dept of Thoracic Surgery

Gulhane Military Medical Academy 06018 Ankara

Turkey

Fax: 903123042900

E-mail:sgurkok@gata.edu.tr

Figure 1

a) Antero-posterior and b) lateral chest radiographs.

\section{Task 1}

Interpret the chest radiographs. 


Answer 1
Chest radiography revealed a normal heartsize,
a right-sided well-defined rounded opacity, den-
sities in the rightlower lobe and a larger opacity
at the base of the right lung.

Ultrasonography (USG) revealed a giant cyst extending to both the thorax and abdomen, which included triple vesicles. Computerised tomography (CT) (figure 2) and magnetic resonance imaging (MRI) (figure 3) were performed to distinguish the location of the cyst.

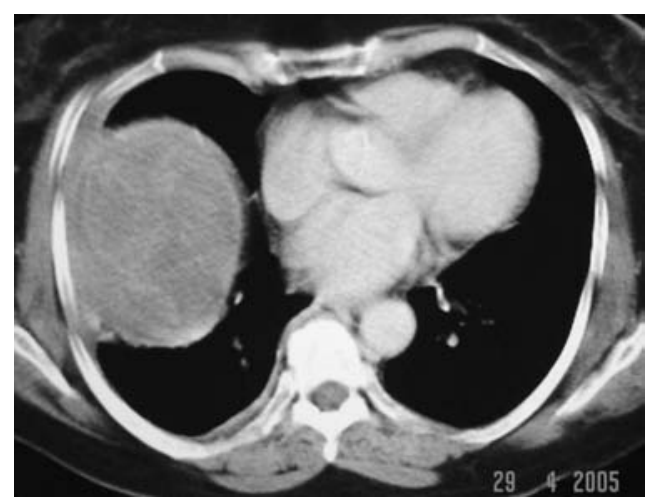

Figure 2

CTscan.

\section{Task 2 \\ Interpret the CT scan and suggest a diagnosis.}

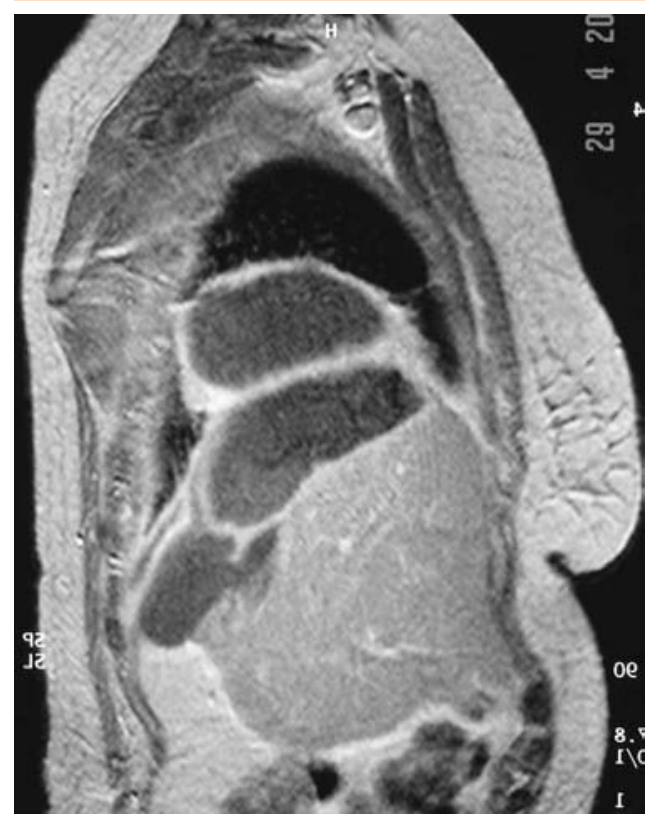

Figure 3

MRIscan.

Task 3

Interpret the MRI scan.

\section{Answer 2}

The $\mathrm{CT}$ showed giant hydatid cysts including multiple vesicles that were adhered to the diaphragm and pushing down on the diaphragm and liver, extending throughout the abdomen.

\section{Answer 3}

MRI revealed a rightsided giant cyst, which was lying between the diaphragm and the superior minor fissure.

The dimensions of the cyst were $12 \times 10 \times 14$ $\mathrm{cm}$. There was a thick capsule formation around the cyst and the radiologist could not distinguish the borders between the diaphragm, liver and the cyst (figure 3).

\section{Task 4}

Based on the findings, what would you do next? 


\section{Answer 4}

Perform a right lower thoracotomy.

During the thoracotomy, two giant infected hydatid cysts were observed between the diaphragmatic layer, free from the lung and abdominal cavity with diameters of $14 \times 13 \times 10$ $\mathrm{cm}$ and $8 \times 8 \times 10 \mathrm{~cm}$. The hydatid cysts originated from the right diaphragm and pushed the diaphragm layer into the abdomen to a great extent. Intra-operative USG was performed for evaluation of the cysts' continuation in to the liver, which revealed no lesions. Subsequently, a cystotomy was performed, and the giant cyst cavity was excised. The diaphragm was repaired using the single suturing technique.

The patient was discharged from hospital on the 6 th postoperative day. Postoperative albendazole therapy ( $10 \mathrm{mg} \cdot \mathrm{kg}^{-1} \cdot$ day $^{1}$ for 2 months) was started when she was discharged from the hospital. At follow-up, 3 months after the operation, the patient was clinically well.

\section{Discussion}

Hydatid disease, caused by Echinococcus granulosus, can be contracted by humans through contact with infected canine faeces. The liver and lung are the most commonly affected sites for the disease, but it can also be seen in other body organs [1]. Rare localisations include the spleen, skin, muscle, brain, pancreas, mediastinum and diaphragm [2-4]. Rare localisation of the disease has been explained by PINNA et al. [5].
Extrapulmonary, intrathoracic hydatid cysts are rare and mostly of mediastinal or pleural origin $[6,7]$. However, a diaphragmatic hydatid cyst is even more rare, with an incidence of $~ 1 \%$. In addition, most of these cases are generally associated with liver hydatidosis. In the few patients with diaphragmatic hydatid cysts, the patients also had a hepatic cyst at the same time as diagnosis or before [8-11]. In the current case, the patient had been operated on for a hepatic cyst 4 years previously.

According to DE VEGA et al. [9], diaphragmatic localisation of a hydatid cyst is possible when the protoscolices reach that site by arterial or lymphatic circulation. In general, diagnosis of a hydatid cyst can be obtained easily through combined assessment of chest radiography, USG and $\mathrm{CT}$. Diaphragmatic hydatidosis requires a careful topographic diagnosis between the lung, diaphragm, liver or abdominal localisations. If there is any suspicion of a relationship, as well as diaphragmatic and hepatic involvement, sagittal and coronal thoraco-abdominal MRI images are more favourable than $\mathrm{CT}$, as in the present case.

The diagnosis of uncommon abdominal sites of hydatid disease is more accurate today because of the new imaging techniques, which are often able to show specific radiological signs of hydatid disease [12]. The treatment of choice is surgical and complete removal of the cyst, but its feasibility is related to the location of the cyst. The optimal strategy is to treat the patients at the noncomplicated stage of the hydatid cyst and, above all, prevent hydatid infestation.

\section{References}

1. Safioleas M, Misiakos EP, Dosios T, Manti C, Lambrou P, Skalkeas G. Surgical treatment for lung hydatid disease. World J Surg 1999; 23: 1181-1185.

2. el Moussaoui A, Rabii R, Rais H, et al. Hydatid cyst of the psoas muscle. Apropos of a case. Ann Urol (Paris) 1997; 31: 357-360.

3. Hafid F, Maiza E, Hammoudi D, Derdar T, Keddari M. Hydatid cyst of the pericardium and diaphragm of a case. Apropos of a case. Pediatrie 1989; 44: 331-334.

4. Eroglu A, Kurkcuoglu C, Karaoglanoglu N, Tekinbas C, Kaynar H, Onbas O. Primary hydatid cysts of the mediastinum. Eur J Cardiothorac Surg 2002; 22: 599-601.

5. Pinna AD, Marongiu L, Cadoni S, Luridiana E, Nardello O, Pinna DC. Thoracic extension of hydatid cysts of the liver. Surg Gynecol Obstet 1990; 170: 233-238.

6. Oguzkaya F, Akçalı Y, Kahraman C, Emirogullan N, Bilgin M, Sahin A. Unusually located hydatid cysts: intrathoracic but extrapulmonary. Ann Thorac Surg 1997; 64: 334-337.

7. Isitmangil T, Toker A, Sebit S, Erdik O, Tunc H, Gorur R. A novel terminology and dissemination theory for a subgroup intrathoracic extrapulmonary hydatid cysts. Med Hypotheses 2003; 61: 68-71.

8. Eren S, Ulku R, Tanrikulu AC, Eren MN. Primary giant hydatid cyst of the diaphragm. Ann Thorac Cardiovasc Surg 2004; 10: 118-119.

9. De Vega DS, Vazquez E, Calvo E, Tamames S. Hydatid cyst of the diaphragm. Apropos of a case. J Chir (Paris) 1991; 128: 76-78.

10. Ersoy G, Yildinr C, Gokgoz S, Ozer T, Tulpar A. Hydatid cyst of diaphragm: a case of hydatid cyst with rare localisation. Mater Med Pol 1993; 25: 109-112.

11. Kabiri H, Al Aziz S, El Maslout A, Benosman A. Diaphragmatic hydatidosis: report of a series of 27 cases. Rev Pneumol Clin 2001; 57: 13-19.

12. Mosca F, Portale TR, Persi A, Stracqualursi A, Puleo S. Uncommon abdominal sites of hydatid disease. Our experience with the surgical treatment of 15 cases. Chir Ital 2004; 56: 333-344. 